\title{
GENÊRO E ESPORTE: QUEBRANDO ESTEREÓTIPOS NAS AULAS DE EDUCAÇÃO FÍSICA
}

\section{RESUMO}

Reinaldo Kovalski de Araujo anrei.rka.rka@gmail.com Universidade Tecnológica Federal do Paraná (UTFPR), Curitiba, Paraná, Brasil.

Vanessa Ukan Alexandre vanessaukan@yahoo.com.br Universidade Tecnológica Federal do Paraná (UTFPR), Curitiba, Paraná, Brasil.
Este artigo nasce dos processos de orientação de conclusão de curso de especialização latu sensu em Gênero e Diversidade Sexual oferecido pela Universidade Federal do Paraná (GDE-UFPR), e busca contribuir com os debates sobre educação física nas escolas, no intuito de superar modelos tradicionais de corpo e movimento separado por sexo. Partindo dessa preocupação, o objetivo é realizar uma análise dialógica do discurso (ADD) a partir de uma materialidade composta por um painel confeccionado ao final de um projeto de intervenção. Para efetuar esse estudo, foram utilizados como metodologia ações pedagógicas dentro das aulas da disciplina de educação física, e os dados separados e analisados a partir da Análise do Discurso, tendo como principais teóricos Bakhtin e o Círculo. Os resultados desse trabalho apontam para a possibilidade de sensibilizar os/as alunos/as e trabalhar questões de diversidade dentro da disciplina de educação física escolar, uma abertura dos/das estudantes para desenvolver atividades que discutam gênero e diversidade sexual na educação física para além de uma separação estanque entre jogos de meninos e jogos de meninas. Observou-se também que a participação de meninas em jogos e brincadeiras que eram socialmente tidas como masculinas e vice e versa possuíam um limitador muito mais social que necessariamente físico ou biológico.

PALAVRAS-CHAVE: Educação física. Gênero. Educação. Bakhtin 


\section{INTRODUÇÃO}

A história tem mostrado, conforme sugere Pereira e Mourão (2005), que o sexo biológico serviu de suporte para a organização social e para a construção de valores. Esta diferenciação foi decisiva para a instalação da hegemonia masculina, que se manifestou em grande parte das relações humanas, em especial no contexto educacional, no qual observamos alguns valores de padrões históricos que separam o masculino do feminino, legitimando a desigualdade.

$\mathrm{Na}$ tentativa de igualar o acesso a métodos educacionais para homens e mulheres, Cruz e Palmeira (2009) lembram que foram criadas as escolas mistas em 1920. Contudo, a relação estabelecida, de superioridade dos homens frente às mulheres, continua até os dias atuais, com os estereótipos e os preconceitos de gênero.

O corpo possui diversos estereótipos sociais, e Louro (2000, p. 8), nos lembra que:

De qualquer forma, investimos muito nos corpos. De acordo com as mais diversas imposições culturais, nós os construímos de modo a adequá-los aos critérios estéticos, higiênicos, morais, dos grupos a que pertencemos. As imposições de saúde, vigor, vitalidade, juventude, beleza, força são distintamente significadas, nas mais variadas culturas e são também, nas distintas culturas, diferentemente atribuídas aos corpos de homens ou de mulheres. Através de muitos processos, de cuidados físicos, exercícios, roupas, aromas, adornos, inscrevemos nos corpos marcas de identidades e, consequentemente, de diferenciação.

Se em algumas áreas escolares a constituição da identidade de gênero e sexual parece, muitas vezes, ser feita através dos discursos implícitos, Louro (1997) afirma que nas aulas de Educação Física, a constituição de um corpo heteronormativo, é geralmente, mais explícito e evidente. A temática de gênero nos debates da Educação Física Escolar, dos esportes e da atividade física é recente, e um dos focos motivadores desses estudos vão ao encontro de superar o modelo tradicional de se pensar o corpo em movimento separado por sexo (PEREIRA; MOURÃO, 2005).

Desde sua introdução nas escolas brasileiras, a disciplina de educação física foi pautada em uma perspectiva médico-higienista, passando pela segregação por gêneros até sua (re)introdução na escola como componente curricular (CASTELLANI FILHO, 1994). Não distante desta realidade, a Educação Física muitas vezes auxilia na consolidação desses conhecimentos deturpados, pois há, incutido na sua cultura, a pseudosuperioridade masculina e a prática constante de movimentos corporais que exigem força e resistência (CRUZ; PALMEIRA, 2009).

Por ter um histórico vinculado à biologia e a manutenção da saúde e da higiene, a disciplina de educação física contribuiu para que justificativas de ordem biológica colaborassem para a separação das turmas femininas e masculinas.

Mesmo com o aporte das novas teorias (ALTMANN, 2009, NASCIMENTO; ALMEIDA, 2007, LOVISOLO, 2006) e com os questionamentos provenientes dos Estudos Feministas, o debate sobre as "[...] diferenças de habilidades físicas" entre os sexos continua controverso na área (LOURO,1997, p. 73).

Com a inclusão dos Parâmetros Curriculares Nacionais, Cruz e Palmeira (2009) alegam que a inclusão de aulas mistas é fundamental, e que houve um avanço nas 
questões de gênero, visando favorecer assim meninos e meninas a serem respeitosos, evitando-se a estereotipia.

Na área da Educação Física a dimensão cultural deveria ter sua importância reconhecida, pois como citam Prado e Ribeiro (2010), a cultura corporal atua diretamente na conformação e domesticação dos corpos, instituindo padrões e estigmatizando práticas que transgridem ao modelo heteronormativo.

Diante disso, e demonstrado a necessidade de refletir sobre o assunto, este artigo parte da reflexão participativa a partir de uma intervenção que teve como objetivo geral desenvolver ações dentro da disciplina de educação física para a quebra de tabus entre gênero e esporte. E, consequentemente, os objetivos específicos deste estudo fora: verificar as dificuldades presentes dentro da prática esportiva relacionadas ao gênero; identificar atividades que reforçam diferenças hierarquizadas entre feminino e masculino; desenvolver práticas pedagógicas que trabalhem com a corporeidade e relações de construções de gênero dentro da realidade escolar.

\section{MÉTODO E INTERVENÇÃO}

Para saber como certas populações se comportam diante de algumas situações, é necessário, como menciona Selltiz (1987), praticar ciência e, através desta, explorar o mundo, para que hajam possibilidades de talvez predizer um futuro.

Quando se trata de pesquisa social, é preciso analisar as variáveis e as relações entre pessoas e grupos, "[...] no âmbito natural em que ocorrem" (SELLTIZ,1987, p. 49). Diante dessa ideia, essa pesquisa buscou em um primeiro momento construir o corpus de pesquisa junto com os estudantes, e em um segundo momento separá-los para uma possível análise.

A escolha da coleta de dados foi feita por meio das características mencionadas por Moreira (2008, p. 2), quando diz que:

Pesquisas de intervenção devem ser realizadas dentro do contexto pesquisado; há uma demanda que necessita a resolução do problema; o pesquisador deve atuar como mediador, articulando os saberes e as atividades propostas, haja interação entre o pesquisador e os sujeitos da pesquisa; as experiências levem a sensibilização e resultados significativos.

O processo de intervenção gerou uma quantidade de enunciados que dialoga com a questão de gênero na escola. Para esse artigo será escolhido somente um dos trabalhos realizados pelo grupo, o chamado mural de fotografias, que será analisado pela Análise Dialógica do Discurso (ADD) com Bhakhtin e o círculo', enquanto materialidades verbo-visuais. Convém relatar, porém, que antes de chegar ao quadro de análise as/os estudantes passaram por um conjunto de ações performativas com o corpo, um conjunto de ações que colocaram em cheque o tabu de um corpo polarizado e dual. Esse processo, que incluiu vivências práticas que serão aqui relatadas, pois fazem parte da construção do corpus de análise. Como docentes, a todo momento presenciamos discursos que visam estabelecer um lugar maior para hegemonia masculina e heterossexual, esses espaços são construídos discursivamente através de falas e gestos, que acabam por reforçar a hegemonia heteronormativa. 
O conceito de ideologia formulado por Bakhtin e o Círculo é de grande validade para compreendermos o funcionamento dessas estruturas, que dão papéis específicos a cada gênero.

Bakhtin (1979, p. 80), longe de estabelecer um conceito de ideologia unicamente marxista, concebe esse termo em dois sentidos, sendo uma ideologia oficial e uma dominante:

A ideologia oficial é entendida como relativamente dominante procurando implantar uma concepção única de produção de mundo.

A ideologia do cotidiano é considerada a que brota e é constituída dos encontros casuais e fortuitos, no lugar do nascedouro do sistema de referências na proximidade social com as condições de produção e reprodução da vida.

Nesse sentido, convém a produção de um trabalho que estabeleça outras interações discursivas, para criar novos campos ideológicos no cotidiano da escola, e em especial nas aulas de educação física.

As intervenções foram realizadas no Colégio Estadual do Campo Doutor Adhelmar Sicuro, de Ensino Fundamental e Médio, que se localiza na Rua Padre José Lopacinski, s/n, no bairro de Catanduvas do Sul, na cidade de Contenda, Estado do Paraná.

Os sujeitos da intervenção foram os/as alunos/as do 3o ano do Ensino Médio, sendo uma turma do período matutino, composta por 21 alunos/as, cuja faixa etária é de 16 a 18 anos, sendo 11 pessoas do sexo feminino e 10 do sexo masculino.

A aplicação da pesquisa ocorreu de agosto a novembro, nas seguintes etapas:

10 Momento: aplicação de questionário, no qual os/as alunos/as responderam questões sobre suas experiências com esportes concebidos, até então por eles/elas, como "masculinos e femininos".

2o Momento: exibição de trechos dos filmes Menina de Ouro e Billy Elliot.

3을onto: vivências práticas de aulas de luta, e aulas de ginástica rítmica.

40 Momento: debate sobre as atividades realizadas, colocações, auto avaliação.

5o Momento: confecção de um painel na qual os/as alunos/as desenvolveram reflexões para a quebra de tabus sobre gêneros e esportes. Divido esse capitulo em dois momentos, para melhor compreensão desta pesquisa. O primeiro momento - Da intervenção - consiste do relato de experiência do processo da intervenção realizada no Colégio Estadual do Campo Doutor Adhelmar Sicuro, onde a partir dos nossos olhares apontamos sentidos, conceitos, significações e diálogos vivenciados por nós e pelas/pelos estudantes sobre as questões que envolvem gênero e diversidade sexual. Fazem parte deste capítulo os seguintes momentos: exibição de trechos dos filmes "Menina de Ouro" e "Billy Elliot"; vivências práticas de aulas de luta e aulas de ginástica rítmica; debate sobre as atividades realizadas, colocações, auto avaliação; confecção de um painel na qual os/as alunos/as desenvolveram reflexões para a quebra de tabus sobre gêneros e esportes.

O segundo momento: análise do painel - confecção de um painel na qual os/as alunos/as desenvolveram reflexões para a quebra de tabus sobre gêneros e esportes. Esse painel constituirá materialidade para o capítulo de análise. No primeiro momento foi aplicado um questionário, o qual foi realizado em sala de 
aula durante uma das aulas de educação física, de forma voluntária e sem identificação

No segundo momento foram expostos os dois 2 filmes, ambos foram assistidos em sala, necessitando de cinco aulas para a conclusão dos mesmos. Foi utilizado como recurso a TV pendrive ${ }^{2}$ pois as mídias foram levadas em pendrive ${ }^{2}$ para uso.

Todo o público da amostra estava presente nesses dias e os dois filmes causaram bastante comoção na turma, algumas frases advindas dos/as alunos/as durante ou após a exibição chamaram a atenção: "Deus me livre ter um pai desse!" citou uma das alunas enquanto víamos Billy Elliot; "Nossa professora, você trouxe um filme muito triste", falou um dos meninos ao final da exibição de Menina de Ouro.

Essas falas nos fazem concluir que o uso de materiais áudio visuais como parte de uma intervenção, em especial os filmes, nesses casos do gênero "drama", colaboram na produção de uma sensibilização, pois fazem com que o/a integrante da amostra materialize seus sentimentos de forma verbalizada, apresentando emoções e sentimentos vivenciados durante a experiência.

Ao final, os pesquisadores abriram espaço para maiores colocações, mas não houve muita interação, e um dos motivos possíveis para isso é devido à comoção dos/as alunos/as, que estavam sensibilizados/as com os finais traçados pelos/as protagonistas. Aproveitando o momento, a professora fez uma fala buscando reiterar a importância da quebra de tabus em relação ao gênero, esporte, corpo e diversidade sexual, focando a dignidade e o respeito ao próximo, abrangendo qualquer diversidade presente, pois como citam Pereira e Castellani (1994) a disciplina de Educação Física também é responsável por momentos para reflexões e práticas que podem aguçar o olhar para a questão das relações de gênero.

Nas aulas seguintes, foi dado sequência às vivências práticas, iniciando com as lutas. A primeira aula foi na própria escola, com exercícios de aquecimento utilizados em treinamento de artes marciais, e movimentos básicos de defesa e ataque, sendo a participação de toda a turma bem satisfatória, pois todos/as conseguiram executar as atividades propostas, sem recusas.

Em um segundo momento, foi realizada uma aula na Academia de Lutas particular $^{3}$, na qual os/as professores/as pesquisadores/as responsáveis lecionaram uma aula de quedas, aproveitando a oportunidade de uso do tatame. Não houve rejeições à participação, e em muitos momentos foram feitos movimentos em que meninos e meninas realizaram quedas um do outro, demonstrando que a técnica é muito mais importante que a própria força, e reforçando que a luta pode ser praticada por ambos os sexos.

\section{ANÁLISE VERBO-VISUAL DOS PAINÉIS}

O painel foi construído tendo como perspectiva a análise verbo-visual dos enunciados:

O termo verbo-visual implica, necessariamente, um enunciado concreto no qual as dimensões verbais e visuais sejam indissociáveis; o verbal e o visual possuem, na dimensão verbo-visual, um lugar que não permite separação, nem valoração de um em detrimento de outro. Ambos são necessários à compreensão do enunciado em seu todo (GONÇALVES, 2013, online). 
Para compreender os conceitos de verbo-visualidade, nos ancoraremos no conceito de Brait (2013), e tomo suas reflexões como ponto de partida para concepção da materialidade aqui analisada.

O termo verbal é compreendido tanto em sua dimensão oral quanto escrita e visual, e abrange a estaticidade da pintura, da fotografia, do jornalismo impresso, e a dinamicidade do cinema, do audiovisual, do jornalismo televisivo, etc. Nesse sentido, o que ganha relevo é a concepção semiótico-ideológica de texto que, ultrapassando a dimensão exclusivamente verbal, reconhece verbal, verbo-visual, projeto gráfico e/ou projeto cênico, como participantes da constituição de um enunciado concreto. Assim concebido, o texto deve ser analisado, interpretado e reconhecido a partir dos mecanismos dialógicos que o constitui, dos embates e tensões que lhe são inerentes, das particularidades da natureza de seus planos de expressão, das esferas em que circula e do fato que ostenta, necessariamente, a assinatura de um sujeito, individual ou coletivo, constituído por discursos históricos, sociais e culturais, mesmo nos casos extremos de ausência, indefinição ou simulação de autoria (BRAIT, 2013).

Com a velocidade da informação, a capacidade tecnológica de registro de dados e as possibilidades multimídias de suporte, a dimensão verbo-visual compõe a linguagem que dá identidade aos sujeitos. As palavras não andam mais solitárias em registros, panfletos, jornais, revistas, etc; aliadas ao discurso estão as imagens, que descasadas nos remetem a outros discursos, ou simplesmente deixam de fazer sentido para um determinado contexto pelo qual se quer comunicar. A articulação entre os elementos verbais e visuais forma um todo indissolúvel, cuja unidade exige do analista o reconhecimento dessa particularidade.

A construção do painel aqui analisado não foi concebida unicamente pelos/as professores/as, mas construídos e orientados a partir das ideias dos/as estudantes, buscando refletir sobre o que ficou de todo aquele processo de vivência corporal.

O estilo do painel parte de um trabalho coletivo. Entendo esse termo como:

[...] conjunto de procedimentos de acabamento de um enunciado. Portanto são os recursos empregados para elabora-lo, que resultam de uma seleção de recursos linguísticos a disposição de um enunciador. Isso significa que o estilo é o conjunto de traços fônicos, morfológicos, sintáticos, semânticos, lexicais... que definem a especificidade de um enunciado e por isso criam um sentido de individualidade (FIORIN, 2008, p. 46)

O painel, constituído de imagens corporais, coloca em evidência o corpo necessário a produzir um discurso dentro da educação física. As disciplinas escolares que trabalham diretamente com o corpo - educação física, dança e teatro - sofrem a todo momento com determinadas demarcações, que estabelecem os limites entre as masculinidades e as feminilidades.

O corpo, entendido aqui como elemento de discurso, carrega em si marcas de aceitação e negação. Esse corpo, composto de um conjunto de enunciados, se constitui enquanto corpo dialógico que se faz ser a partir de um determinado conjunto de enunciados.

O corpo é investido incessantemente de discursos; esses o compõem e lhe dão forma, pois diariamente os discursos que são lançados sobre o corpo nos dão identidades, reorganizam nossa forma de ver e redesenhar nosso modo de ser e estar no mundo. É na vida cultural, nos processos cotidianos, que aprendemos a 
ser homens e mulheres, e damos a cada um desses gêneros papéis específicos, atribuindo a cada um, uma performance de corporal. Historicamente a educação física escolar estabeleceu o conceito de virilidade e atleta ao masculino, relegando às mulheres o papel de espectadoras, torcedoras ou quando muito participadoras recreativas desses eventos esportivos ou esportivos escolares.

Icle (2013) nos conduz a refletir em como o sujeito ao seu redor está carregado de agentes que procuram estabelecer uma forma correta de ser, de se vestir e até de se comportar nos processos de interação social. As interações colaboram com o que significa ser homem e mulher. Nosso corpo não nasce nu, mas sim coberto de discursos que o constituirá dia a dia.

Os painéis foram divididos em 2 grupos, que chamarei aqui de:

Grupo 1 - Coisas feitas por eles - constitui-se de um conjunto de imagens de homens dançando ballet, jazz, dança contemporânea e ginástica artística, com um letreiro "Gênero x Esportes - Quebre seus Tabus";

Grupo 2 - Coisas feitas por elas - constitui-se de um conjunto de imagens de mulheres lutando, jogando futebol e futebol americano, com um letreiro "Gênero x Esportes - Quebre seus Tabus".

Figura 1 - Grupo 1

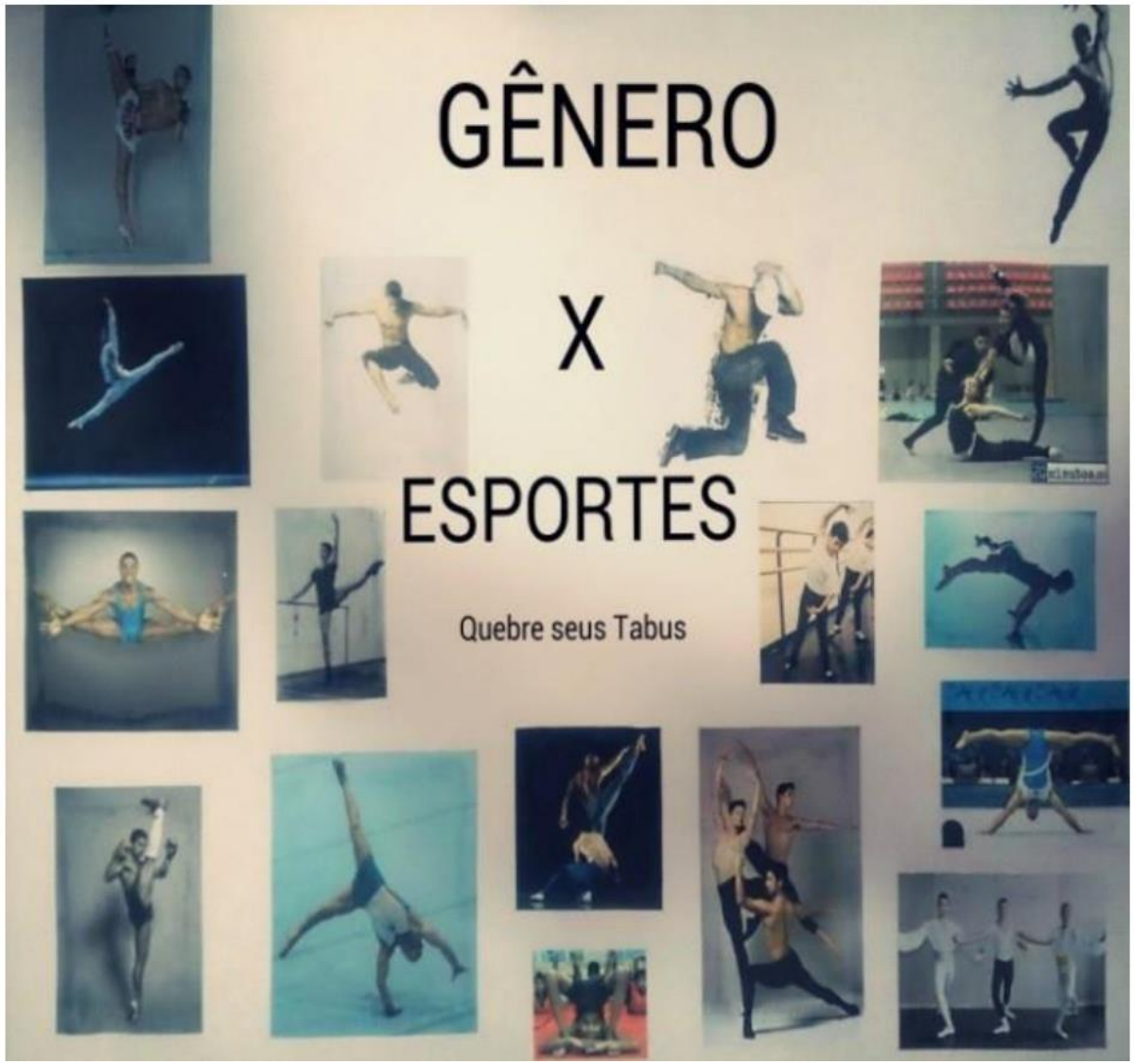

Fonte: Foto da autora 


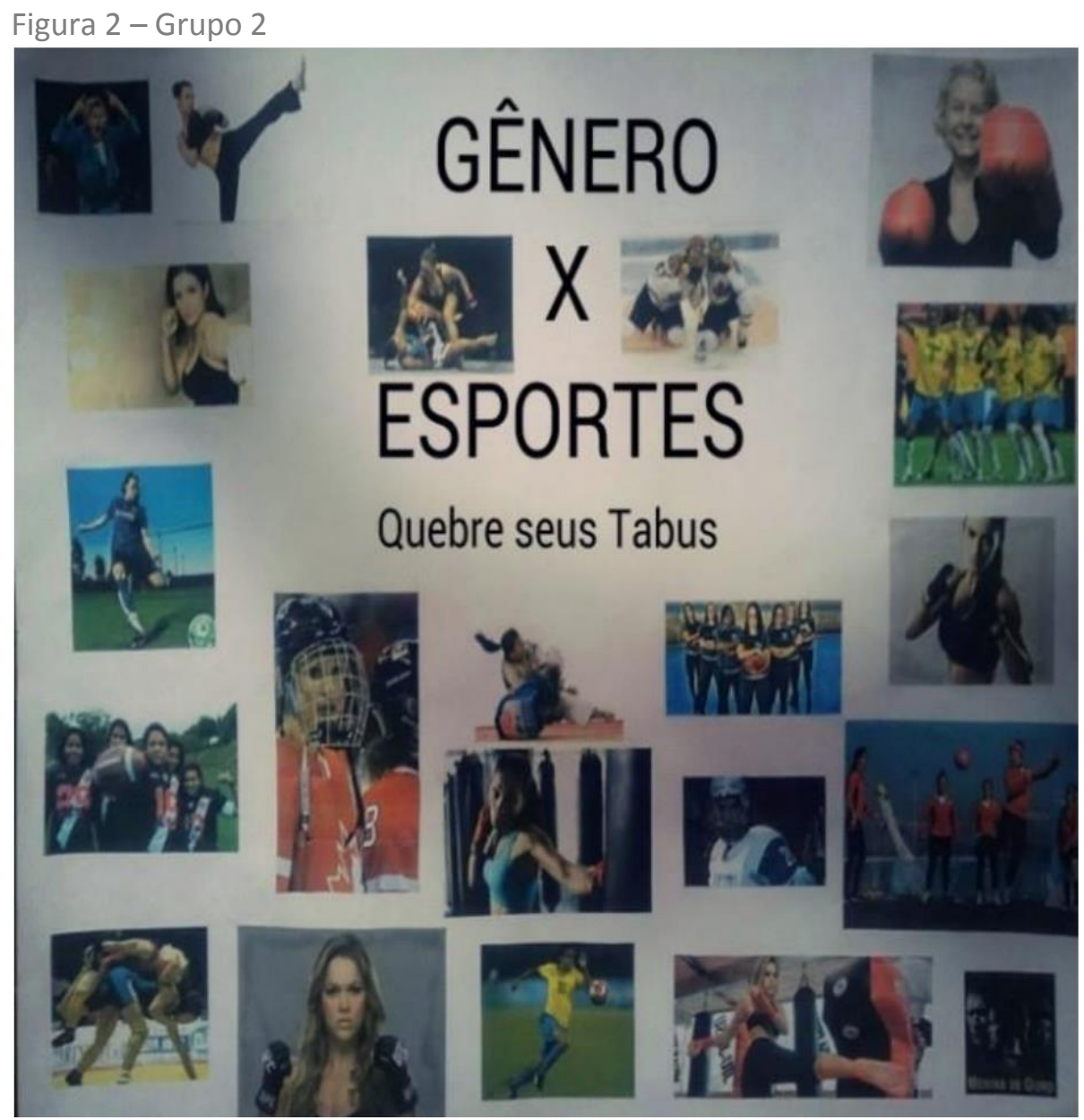

Fonte: Foto da autora

Dentro da análise dialógica do discurso não existe enunciado sem sentido:

Quanto ao outro futuro, aquele que vai ler e atribuir um sentido ao texto, também ele é presentificado na medida em que um texto é um objeto que pede para ser lido, que convoca outras vozes, e que só adquire existência no momento em que alguém se dispõe a habitá-lo e por ele ser habitado. (AMORIM, 2004, p. 164).

Nesse contexto, os painéis, mesmo sendo uma sucessão de colagens, carregam sentidos que ultrapassam a simples escrita verbal, sentidos estes que se comunicam com o visual, proliferando vários outros efeitos de sentidos, que por sua vez falam sobre o lugar do homem e da mulher na visão dos/as estudantes pesquisados/as.

Em um primeiro olhar, pelos quadros é notável que os/as estudantes colocaram em destaque esportes que são cotidianamente praticados por homens sendo praticados por mulheres, e esportes (e trabalhos artísticos) cotidianamente praticados por mulheres sendo praticados por homens. Nessa proposta construíram uma inversão de valores, brincando com o símbolo ideológico.

A personagem que se apresenta própria do corpo não é mais a personagem que se espera; ela transgride e lança os limites desse corpo para outras esferas de possibilidades. Essa esfera de possibilidades dialoga com as experimentações 
vivenciadas durante as aulas práticas anteriores, sejam as de luta para as meninas sejam as de dança para os meninos.

Um dos detalhes a ser destacado na imagem verbo-visual é que as imagens pouco ou nada se relacionam com o cotidiano da educação física escolar. É importante destacar que a escola pública, em razão da escassez de materiais, impossibilita uma oferta que vá ao encontro da variedade de possibilidades que os/as estudantes merecem como lutas, danças, esportes diversos, etc. Esse projeto só foi possível graças à parceria firmada pela autora com amigos/as e conhecidos/as.

Ao nosso olhar, como pesquisadores/as entendemos os/as personagens ali representados/as como uma representação das vivências realizadas pelos/as estudantes durantes as aulas práticas, o que Amorim (2004, p. 258) afirma:

[...] eu, enquanto pesquisador, escuto o outro a partir da minha própria problemática, de meu objeto de pesquisa; quando relato ou simplesmente reflito a propósito do que ele me diz, não estou apenas repetindo o que ele me disse. Em uma palavra: eu não sou dele. De sua parte, ele também não é meu: naquilo que me diz que o que ele está fazendo não é apenas ilustrar minha teoria ou responder a minha pergunta.

Assim, é válido ressaltar que a análise está aberta a outros olhares e interpretações, e o/a analista pesquisador/a realiza, a partir de seu campo de atuação, de seu lugar de vivência e ponto de partida. Nesse processo é válido ressaltar que outras formas de interpretação do protocolo também poderiam ser agregadas, o que na visão de Bakhtin e o Círculo transforma o enunciado não em um sistema fechado de signos, mas numa possibilidade infinita de sentidos.

Os quadros deixam claro que os/as estudantes buscaram imagem com intuito de quebrar tabus, ou seja, mostrar que esportes socialmente considerados masculinos podem e são realizados por mulheres, e vice-versa. Porém, é evidente que os esportes que estariam relacionados, nessa lógica, ao sexo feminino, seriam aqueles mais ligados às artes, como a dança, o nado sincronizado, a ginástica artística, enquanto os esportes relacionados ao masculino seriam os relacionados à força física, mesmo sendo ambos os esportes utilitários de grande força física, o que faz cair por terra o mito da força relacionada a masculinidade.

Temos, então, uma tensão entre estética e força, sendo a primeira considerada predominantemente feminina e a segunda predominantemente masculina. São nessas esferas discursivas que são criadas relações que traçam estigmas ao corpo, delimitando limites e espaços, os chamados interdiscursos, criados entre as relações verbais e os contextos, sendo concebido como seu acabamento avaliativo (BRAIT, 2013).

A partir dos anos 1930, com a introdução do esporte moderno no conteúdo da educação física escolar no Brasil, a mulher mais do que nunca passou a ser vista como um corpo frágil, incapaz de realizar as mesmas atividades que os homens, pois essas eram tidas como possuidoras de forças limitadas. Porém, era designada a elas os esportes relacionados às danças e às artes; instaurava-se assim uma naturalização da docilidade e sentimentalismo do corpo feminino, qualidades que eram ao mesmo tempo negadas ao homem por essa mesma "natureza".

O corpo masculino que discursava essa característica "divinamente" feminina era considerado anormal, desviante, sendo sua masculinidade e virilidade questionada a toda prova, logo que só era possível uma maneira de ser homem, a socialmente construída e investida de signos e sentidos. 
Mexer o corpo, de forma a buscar uma plasticidade dos movimentos, é entendido dentro do processo heteronormativo das aulas de educação física como coisa de menina e, consequentemente, o menino que busca essa plasticidade corporal é compreendido como "bixa", "veado", "mulherzinha".

Já os exercícios que empreendem forças são tidos como incapacitantes para as meninas, pois essas ainda carregam dentro da construção de suas feminilidades uma ideia de fragilidade, onde qualquer empreendimento de uma força maior poderá machucar, agredir ou ferir seus corpos, impossibilitando desta forma a reprodução.

Nota-se que, diferente dos discursos que permeiam a esfera dos meninos ao fazerem atividades de caráter plástico - o que deslegitima seu corpo de uma masculinidade hegemônica -, as feminilidades das meninas, por sua vez, não são questionadas ao executarem atividades de força; o que é questionado é sua capacidade de realizar de forma satisfatória os exercícios propostos. Louro argumenta que (1992, pp. 58-59)

[...] todo movimento corporal é distinto para os dois sexos: o andar balançando os quadris é assumido como feminino, enquanto dos homens espera-se um caminhar mais firme (palavra que no dicionário vem associada a seguro, ereto, resoluto - expressões muito masculinas e positivas), o uso das mãos [...], o posicionamento das pernas ao sentar, enfim, muitas posturas e movimentos são marcados, programados, para um e para outro sexo.

Considerando as relações discursivas entre os gêneros, uma categoria relacional há de repensar como sua reverberação constitui corpos e os renegam ou os negam. O conjunto de discursos que é atribuído ao corpo como seu gênero, sua idade, sua sexualidade, sua habilidade, formam um emaranhado de sentidos que faz daquele corpo capaz de ocupar ou não um determinado espaço.

\section{FINAL DE JOGO, OU PRORROGAÇÃO?}

Podemos concluir, a partir das vivências dessa pesquisa, que a palavra mulher nas aulas de educação física vem acompanhada de um conjunto de saberes sobre seus copos, que dizem sobre fragilidades, habilidades, espaços. etc. Ademais, outros corpos também são carregados de sentidos similares, como os dos meninos que não "gostam de educação física" ou que não possuem o mesmo vigor para as aulas, sendo esses taxados de gays, incapacitados ou diferentes.

Nesse sentido, o papel da profissional de educação física é de extrema importância, pois segundo Turne (1993) a presença de adultos entre jovens como orientadores para práticas de esportes, diminui consideravelmente a separação entre os gêneros, pois esse pode, a partir de questões que são levantadas na efemeridade do evento, incentivar discussões sobre igualdade e equidade.

Analisando os discursos presentes nessa pesquisa, nota-se que ainda muito há de se mudar, tanto dentro quanto fora da escola. Ainda temos na mídia uma hipersexualização da mulher no esporte, e dentro dos campos escolares temos meninas tomando poucos espaços de usos, como quadras esportivas, por exemplo.

Cena comum nas escolas é vermos constantemente quadras esportivas sendo tomadas por meninos, e meninas sendo relegadas a pequenos cantos com bolas, 
praticando suas atividades em lugares escondidos onde pouco aparece sua performance.

Esse processo teve como cerne a possibilidade de experimentar e sentir processos sinestesicamente, coisas que talvez os/as estudantes, em virtude de suas limitações corporais e falta de oportunidade, nunca pudessem vivenciar. Para além de uma prática corporal, que seria impossível de descrever aqui, pois o sentir apenas se vivência, a discussão ao final de cada processo demonstrou como o conceito que cada um tinha das atividades era carregado de estereótipos e preconceitos.

Observamos também que os exercícios realizados pelas meninas, que habitualmente eram tidos como coisas de meninos, eram encarados como uma marca de superação. Participar das lutas, ir até o final, era tido como resistência; poucas viam nesse processo uma de brincadeira. Para os meninos, os trabalhos que envolviam dança, como ballet e ginástica, carregavam em si o tom de carnavalização onde os mesmos suspendiam a seriedade do processo para poder brincar de ser, fazer de conta, blindar dessa forma sua masculinidade com uma personagem.

Esse conceito nos remete de imediato ao signo Carnaval. Porém, é necessário esclarecer que, dentro da arquitetônica bakhtiniana, este signo possui um significado diferente do que a maioria das pessoas entende, atualmente, por carnaval, qual seja, um espetáculo de desfiles, que acontecem em um local fechado para um público restrito assistir ou ver por televisão. Bakhtin considera o carnaval como festa popular universal, que se passa no espaço público aberto da cidade (ruas, praças), como momento de liberação das relações hierárquicas de poder, êxtase do ser, rompimento de regras e tabus, sem privilégios e assimetrias, apontando para um tempo futuro incompleto, de renovações. A lógica desse carnaval dionisíaco é a do homo demens que o transforma no lócus privilegiado da inversão, da ridicularização e da desobediência a tudo que seja oficial.

Seu traço principal é o avesso que se pode evidenciar com permutações entre o alto (cabeça, face = espírito, dignidade, sagrado, puro) e o baixo (traseiro, genitais = obsceno, profano, sujo). Esses traços se evidenciam no que Bakhtin chama de corpo grotesco, que está em constante movimento em torno do cosmos e seus quatro elementos: água, ar, terra e fogo. Estes elementos, submetidos às leis cósmicas, anunciam nascimento e morte de todas as coisas da terra. Ao contrário do corpo estético padrão do homo sapiens apolíneo, o corpo grotesco não coloca a sexualidade como raison d'être da existência humana, uma vez que os verbos utilizados para caracterizá-lo estão no mesmo eixo sintagmático, sem hierarquias. Desse modo, urinar, arrotar, trepar, comer, beber, cuspir, defecar etc. nos remetem a travessuras e diabruras típicas do carnaval, o que nos permite estabelecer um diálogo com o outro por meio do livre contato - não há diferença entre classes sociais, pois no espaço aberto das ruas e praças todos/as podem brincar, pular, dançar como desejam. Todas as fantasias são permitidas. Por exemplo, um homem do campo pode sair vestido de rei, uma senhora rica pode fantasiar-se de prostituta, homens se vestem de mulheres.

Tal fato atesta a fragilidade das construções das masculinidades, que buscam a todo momento escudos para não perder sua legitimidade. 


\title{
GENDER AND SPORT: BREAKING STEREOTYPES IN THE LESSONS OF PHYSICAL EDUCATION
}

\begin{abstract}
This article aims to contribute to the debates about physical education in schools in order to overcome the traditional models of body and movement separated by sex. Based on this concern, the goal is to propose actions within the discipline of physical education to break down taboos between gender and sport. In order to carry out this study, the pedagogical actions within the classes of the discipline of physical education were used as methodology, and the data were separated and analyzed from the Discourse Analysis, with the main theorists Bakhtin and the Circle. The results of this work point to the possibility of sensitizing students and working on diverse issues within the discipline of physical education of the school, opening students to develop activities that discuss sexual and gender diversity in physical education and discuss them beyond a Separation between the games of the boys. And girls games. It was also observed that the participation of girls in games and games considered socially masculine and vice versa had much more social constraints than necessarily physical and / or biological.
\end{abstract}

KEYWORDS: Gender. Physical education. Bakhtin; Education 


\section{NOTAS}

1 Segundo Brait (2009), o pensamento Bakhtiniano não é constituído apenas pelos escritos do filosofo da linguagem Mikhael Bakhtin, mas também por um grupo de intelectuais de diferentes áreas que com ele participaram na Rússia compreendida entre os anos de 1920 e 1970, de vários e produtivos círculos de discussões e construção de uma postura singular em relação a linguagem e seu estudo. 2 Aparelho disponível nas salas de aula da rede pública estadual do Paraná.

${ }^{3}$ As aulas de luta foram feitas em parceria com um amigo que possuía uma academia de luta próximo a escola. Foi possível, graças a essa parceria, uma troca de conhecimentos entre o professor e os/as estudantes, também uma utilização do espaço físico e dos materiais.

\section{REFERÊNCIAS}

ALTMANN, Helena; AYUOB, Eliana; GARCIA, Emília Fernandez. Educação Física Escolar e Igualdade de Gênero: Um Estudo Transcultural - Primeiras Aproximações. Anais do XVI Congresso Brasileiro de Ciências do Esporte e III Congresso Internacional de Ciências do Esporte. Salvador - Bahia - Brasil 20 a 25 de setembro de 2009.

AMORIM, Marilia. O pesquisador e seu outro: Bakhtin nas ciências humanas. São Paulo: Musa Editora, 2004.

BAKHTIN, Mikhail Mikhailovitch, et al. Marxismo e filosofia da linguagem: problemas fundamentais do método sociológico na ciência da linguagem. São Paulo: hucitec, 1979.

BRAIT, Beth. Bakhtin e o círculo. São Paulo: Contexto. 2009

BRAIT, Beth. Construção coletiva da perspectiva dialógica: História e alcance metodológico. In: FÍGARO, Roseli. (org) Comunicação e análise do discurso. São Paulo: Contexto, 2012, p.79-98.

BRAIT, Beth. Tramas verbo-visuais da linguagem. In: BRAIT, Beth. Literatura e outras linguagens. São Paulo: Contexto, 2013.

CASTELLANI FILHO, Lino. Educação Física no Brasil: a história que não se conta. 4 ed. Campinas: Papirus, 1994.

CRUZ, Marlon Messias Santana; PALMEIRA, Fernanda Caroline Cerqueira. Construção de identidade de gênero na Educação Física Escolar. Revista de Educação Física Motriz. Rio Claro. v.15 n.1 p.116-131, jan./mar, 2009.

FIORIN, José Luiz. Introdução ao pensamento de Bakhtin. São Paulo: Ática, 2008. GONÇALVES, Jean Carlos O corpo em discurso: Reflexões bakhtinianas a partir de protocolos teatrais verbo-visuais. Revista Polifonia, Cuiabá: UFMT, em caso de aprovação o artigo será publicado no volume 20, n 27, 2013. 
ICLE, Gilberto. Da performance na educação: perspectivas para a pesquisa e a prática.

PEREIRA, Marcelo de Andrade (org.). Performance e Educação: [des]territorializações pedagógicas. Santa Maria, RS: Editora UFSM, 2013. p. 9 - 22.

LOURO, Guacira Lopes. $\mathbf{O}$ corpo Educado: pedagogias da sexualidade. 2‥ Ed. Belo Horizonte: Autêntica, 2000.

LOURO, Guacira Lopes. Uma leitura da história da educação sob a perspectiva de gênero. Teoria e Educação, no 6. Porto Alegre, 1992, pp. 53-67.

NASCIMENTO, Paulo Rogério Barbosa do; ALMEIDA, Luciano de. A tematização das lutas na Educação Física Escolar: restrições e possibilidades. Revista Movimento, Porto Alegre, v. 13, n. 03, p. 91-110, setembro/dezembro de 2007.

PEREIRA, Sissi Aparecida Martins; MOURÃO, Ludmila. Identificações de gênero: jogando e brincando em universos divididos. Revista de Educação Física Motriz. Rio Claro. v.11 n.3, p.205-210, set./dez. 2005.

PEREIRA, Mateus Camargo; CASTELAN, Lia Polegato. Relações De Gênero E Educação Física Escolar: Possibilidades Pedagógicas. Revista Coleção Pesquisa em Educação Física - Vol.10, n.4, 2011.

DO PRADO, Vagner Matias; MIRANDA RIBEIRO, Arilda Ines. Gêneros, sexualidades e Educação Física escolar: um início de conversa. Motriz-revista de Educação Física. Rio Claro: Univ Estadual Paulista-unesp, Inst Biociencias, v. 16, n. 2, p. $402-$ 413, 2010. Disponível em: <http://hdl.handle.net/11449/6729. Acesso em: 20/02/2015.

THORNE, Barrie. Gender play: Girls and boys in school. New Jersey: Rutgers University Press, 1993, 237pp.

SELLTIZ, Wrightsman. Métodos de pesquisa nas relações sociais. 4 ed. São Paulo: Epu,1987.

Recebido: 20 de maio de 2017.

Aprovado: 28 de junho de 2017

Como citar:

ARAÚJO, Reinaldo Kovalski de; ALEXANDRE, Vanessa Ukan. Gênero e esporte:

quebrando estereótipos nas aulas de educação física. Cad. Gên. Tecnol., Curitiba,

v. 10, n. 35, p. 69-82, jan./jun. 2017.

Correspondência:

Reinaldo Kovalski de Araujo

Rua Agnelo Florêncio Ribeiro, 383

CEP: 83420-000 - Quatro Barras-PR

Direito autoral:

Este artigo está licenciado sob os termos da Licença Creative Commons-Atribuição 4.0 Internacional.

\section{(c) (1)}

